\title{
OMAE2019-95913
}

\section{SPATIAL AND SEASONAL VARIABILITY OF METOCEAN DESIGN CRITERIA IN THE SOUTHERN SOUTH CHINA SEA FROM COVARIATE EXTREME VALUE ANALYSIS}

\author{
Vadim Anokhin \\ Sarawak Shell Bhd \\ Kuala Lumpur, Malaysia \\ David Randell \\ Shell Global Solutions BV \\ Amsterdam, Netherlands
}

\author{
Emma Ross \\ Shell Global Solutions BV \\ Amsterdam, Netherlands
}

\author{
Philip Jonathan \\ Shell Research Ltd., London, UK \\ Lancaster University, UK
}

\section{ABSTRACT}

This paper describes spatial and seasonal variability of metocean design criteria in the southern South China Sea. Nonstationary extreme value analysis was performed using the CEVA approach (Covariate Extreme Value Analysis,[1]) for a 59-year long SEAFINE hindcast of winds and waves, estimating metocean design criteria up to 10,000-year return period. Wind design criteria are mostly driven by large-scale monsoonal events; at higher return periods infrequent cyclonic events have strong influence on the tail of the extreme value distribution but confined to a limited geographical area. The CEVA analysis of waves showed much less dependence on the tropical cyclone events; the spatial metocean design criteria were smoother, mostly influenced by the monsoonal wind strength, fetch and local bathymetry. Return value estimates illustrate the strong seasonality of metocean design criteria, with boreal winter (December-February, Northeasterly monsoon) contributing most to the extremes, while April and May are the mildest months. Estimates for the ratio of 10,000/100-year return values are also presented, both for winds and waves. There is empirical evidence that the range of "typical" values of generalised Pareto shape parameter observed for Hs is different to that observed for wind speed. For this reason, an upper bound of +0.2 for generalised Pareto shape was specified for wind speed analysis, compared to 0.0 for Hs. In some cases, increase of upper bound for waves to 0.1 is justified, leading to slightly more conservative $H$ s values. We confirmed that the upper end point constraint was not too influential on the distributions of generalised Pareto shape parameter estimated. Nevertheless, it is apparent that specification of bounds for generalised Pareto shape is a critical, but problematic choice in metocean applications.

Keywords: Metocean, Design Criteria, Extreme Value Analysis, Return Value, Offshore Structures, Monsoon, Tropical Cyclone, South China Sea

\section{INTRODUCTION}

Accurate metocean design criteria are important for safe and reliable design and operations of offshore facilities. The southern South China Sea (SCS) region (Figure 1) is exposed to seasonal monsoons and tropical cyclones (typhoons), which drive the extreme winds, waves and currents. SCS is a semi-enclosed marginal sea, bounded by China from the north, Vietnam and Peninsular Malaysia (PM) from the west, Borneo Island from the south and Philippines archipelago and Taiwan from the east. In its central region, SCS reaches depths of over $5,000 \mathrm{~m}$, with the average depth of $1,200 \mathrm{~m}$. The continental shelf stretches along the eastern side of the basin, relatively narrow along the Vietnam coast, but widening further south into the Sunda Shelf (Figure 1). In this region the water depth averages only $60-100 \mathrm{~m}$, with numerous scattered shoals and coral atolls. From central Borneo to Palawan Island the continental shelf narrows dramatically, extending only by about $100-150 \mathrm{~km}$ offshore.

Weather patterns in the SCS region are governed by the seasonal monsoons: the East Asian Summer Monsoon ([2], [3], [4], [5]) observed from May to September and characterised by southwesterly winds; and the western North Pacific Monsoon (North-East Monsoon), with strong northeasterly winds recorded from mid-November to early March across the entire region. The transitional inter-monsoonal periods are observed from April to May and from September to October when the winds are light and variable in direction.

Tropical Cyclones, which in the West Pacific are referred to as Tropical Storms and Typhoons, also contribute to the extreme weather in the SCS ([6], [7], [8]). Tropical cyclones are observed throughout the year, with the peak of cyclonic activity around August-September, when typhoons form in the Pacific, east of Philippines, and then track west- or northwestwards towards mainland China, either making a landfall or re-curve to the 


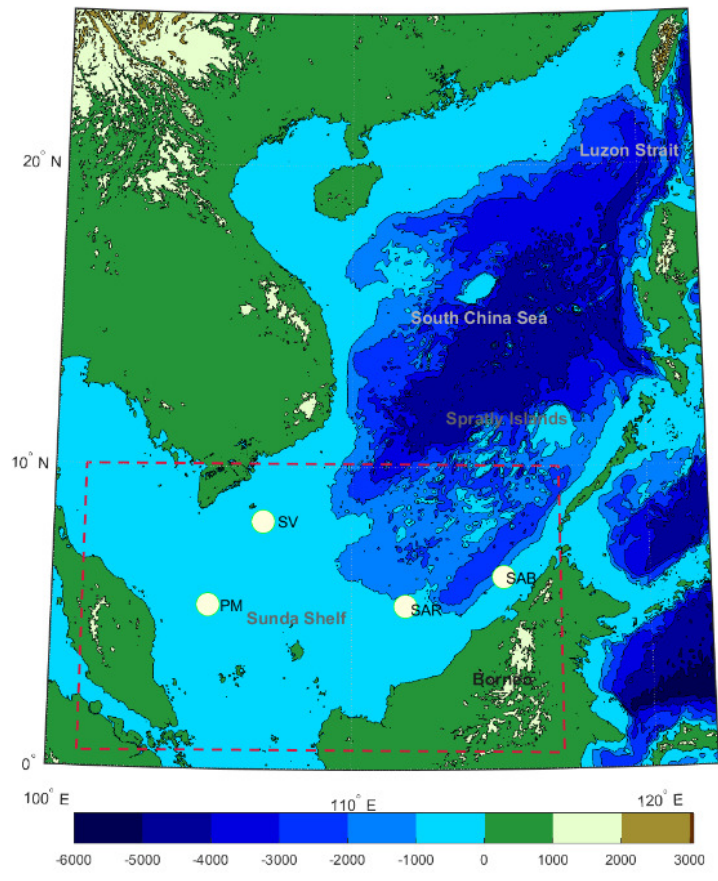

Figure 1: Location map and study area

northeast. In the southern SCS, peak cyclonic activity is observed later in the year, around October-November (Vietnam coastline) or late December-early January (waters offshore Borneo).

Occasionally, cyclones form in the southern SCS itself [9]. The systems rarely reach Tropical Storm strength, tracking as Tropical Depressions, although some can develop into a typhoon. Only a few cyclones approach coastal waters or make landfall, impacting offshore and onshore O\&G facilities (Figure 2). Some of these are discussed below.

Typhoon Percy originated in the southern SCS in November 1983, and rapidly intensified to typhoon strength as it moved southwards. The weak steering winds resulted in the typhoon slowing down, meandering, and later changing its direction to northeasterly, making landfall over Philippines. Typhoon Sally formed in late November 1974 north of Sabah and tracked across the southern SCS, reaching typhoon strength before entering the Gulf of Thailand (GoT). Typhoon Gay formed south of Vietnam in November 1989, and rapidly intensified as it moved westwards into the Gulf of Thailand. This was the strongest typhoon in the GoT in the past 35 years and the first typhoon to make landfall in central Thailand in over a century. Tragically, the storm caused over 800 unconfirmed fatalities along the Thai coast and resulted in the sinking of the drillship Seacrest with a loss of 91 lives. Tropical Storm Greg formed in the central part of southern SCS in December 1996, and tracked eastwards, towards Borneo, making a very rare landfall on Sabah coastline. The storm generated winds in excess of 45 knots and resulted in numerous deaths in Sabah due to flooding. Lastly, Tropical Storm Vamei formed in December 2001 west of Borneo Island, and tracked towards Peninsular Malaysia, making landfall around Johor and Singapore. This storm was an example of very rare equatorial cyclone [10], which produced sustained winds in excess of $25 \mathrm{~ms}^{-1}$ and caused widespread damage along its path.

Tropical cyclones can also affect monsoonal winds. During the surges of the Northeasterly monsoon, tropical cyclones often get imbedded into large-scale monsoonal flows, thus enhancing monsoonal winds on the leading edge of the cyclone. In boreal summer, distant typhoons in the Pacific can amplify southwesterly winds offshore Borneo and Vietnam, with winds occasionally reaching $10-15 \mathrm{~ms}^{-1}$.

The SCS wave climate shows strong spatial, seasonal and directional variability. Waves are strongly influenced by the wind speed and direction, duration of the event and effective fetch [11]. Fetch length also affects significant wave height (Hs) and corresponding peak spectral wave period (Tp) [12]. During the surges of the Northeasterly monsoon, strong winds, often reaching gale force, blow across the entire length of the SCS, resulting in high waves offshore southern Vietnam (SV), Peninsular Malaysia (PM) and the Sarawak region of Borneo island (SAR). The winds are strongest off the southern tip of Vietnam, where despite a shorter fetch waves are highest, while waters offshore Malaysia are influenced by the land topography and the presence of the Borneo Vortex [13], resulting in lower wave heights. In the intermediate and shallow waters across the continental shelf, the effect of bathymetry becomes apparent. Wave attenuation, refraction, and shoaling leads to lower wave heights observed on Sunda Shelf and over continental shelf offshore Borneo.

The weaker East Asian Summer Monsoon is characterized by south-westerly winds, which can be amplified by the passage of distant typhoons further north. In response to monsoonal winds, waves along Borneo coast can intensify, although they are generally lower compared to winter season, due to shorter fetch and weaker winds.

Metocean design criteria in the southern SCS have been used for design of offshore structures since early 1970s. While old design recipes relied on 1 and 100-year return period (RP)

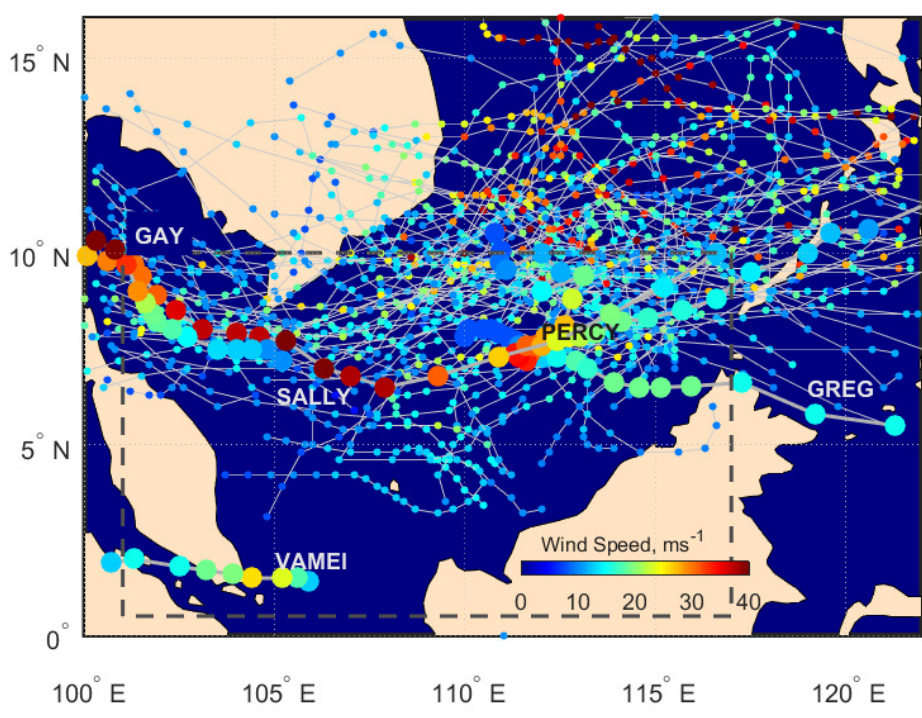

Figure 2: Tropical cyclone tracks, highlighted by intensity 
design criteria to estimate design loads (operational and extreme cases), the new structural codes often require very low probability $(1,000$ to 10,000 -year return period) metocean criteria to determine abnormal design case [14]. The length of the tail of the extreme value distribution, quantified in terms of the ratio of 10,000-year to 100-year return values, is an important parameter for design of offshore structures, particularly for fixed steel platforms with the L1 exposure level [15]. New design checks require testing a platform structure against an abnormal design case [14]. Assessment of platform air gap also requires extrapolation of total water level to 1,000-year or 10,000-year return values.

Extremes for winds, waves, water levels and currents are traditionally extrapolated from measured or hindcast data using extreme value analysis (EVA) tools by applying Weibull, Gumbel or Generalized Pareto distributions to the storm peaks. This approach is often refereed as the historical method and is well described in [16]. The disadvantage of the historical method is that the extrapolation to the extremes beyond 100-year return period is often associated with very high uncertainty due to limited duration of the available databases, biases introduced by the selection of the analytical model (Weibull, Gumbel, GPD), selection of thresholds for storm identification, and data fitting routines [17]. Recently, new deductive methods for data extrapolation were developed. These rely on non-stationary extreme value analysis, hereafter referred to as CEVA ("Covariate Extreme Value Analysis") and are described in ([1], [18], [19], [20]). Briefly, CEVA performs a non-stationary directional-seasonal analysis of storm peak significant wave height using a penalized maximum likelihood approach. Directional and seasonal variation of extreme value threshold and generalised Pareto model parameters are represented by tensor-products of B-splines, penalized to achieve optimal predictive performance. Within-storm evolution is characterised using a library of historical storm events, and standard (e.g. Forristall distributions) are adopted for short-term responses (e.g. for maximum wave height in a sea state). Uncertainties in all inferences are quantified using bootstrap resampling. The

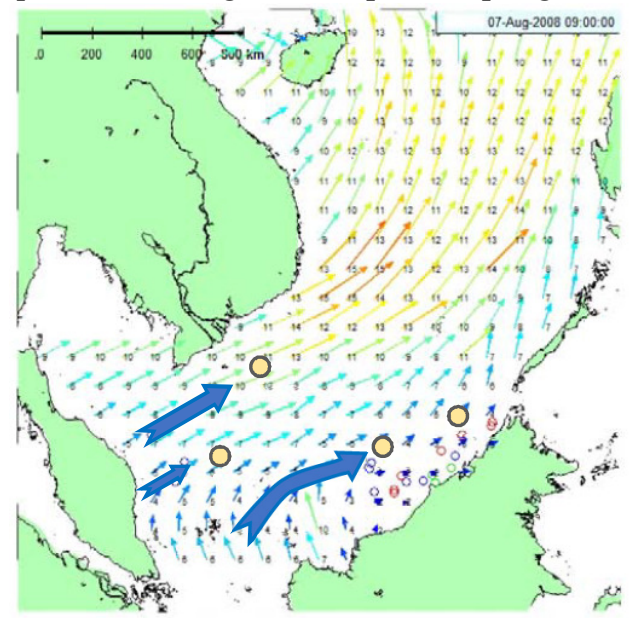

CEVA method allows the estimation of $\mathrm{N}$-year return period criteria for selected parameters and yields consistent design criteria by incorporating seasonal and directional variability into the calculations. [21] presented a method to derive the marginal distributions of winds speed and Hs using Compound Extreme Value Distribution, applying it to a location in northern SCS. The authors concluded that Gumbel and GPD are best suited for extrapolations of winds, but the former is usually adopted for engineering studies as it provides more conservative estimates.

This paper applies CEVA methodology to a 59-year long hindcast of winds and waves (SEAFINE) to derive spatially consistent metocean design criteria in the southern SCS region. The seasonal and spatial variability of extremes for various return periods is discussed. An attempt is made to understand the drivers of the slope of the extreme value distribution (that is, the ratio of 10,000-year to 100-year events) by analyzing the contribution of individual extreme 'black swan' events (typhoons in this case) to the design criteria corresponding to very low probability. We note that the CEVA methodology allows derivation of the extreme total water levels from wave crests, tides and storm surge [1], but this was not considered in the present study, as the storm surge and tidal data was not readily available at all locations, and the computational time to include short-term variability at all grid points would be prohibitively long.

\section{METHODS}

\subsection{Input Data}

The SEAMOS South Fine Grid Hindcast (SEAFINE) was developed by an OGP Joint Industry Project (JIP), administered by Oceanweather, Inc. The hindcast aimed at providing reliable wind, wave and currents data on meteorological and oceanographic extreme and operational conditions in the SCS region, and spans from July 1956 to June 2016 [22]. The continuous wave model was run over the study area on $28 \mathrm{~km}$ ( 0.25 degree) grid domain, while higher resolution 0.05 degree $(\sim 5.5 \mathrm{~km})$ covered the area from $14.5^{\circ} \mathrm{N}-30^{\circ} \mathrm{N}$ and $99^{\circ} \mathrm{E}-$ $130^{\circ} \mathrm{E}$ and applied the courser model boundary spectra along its

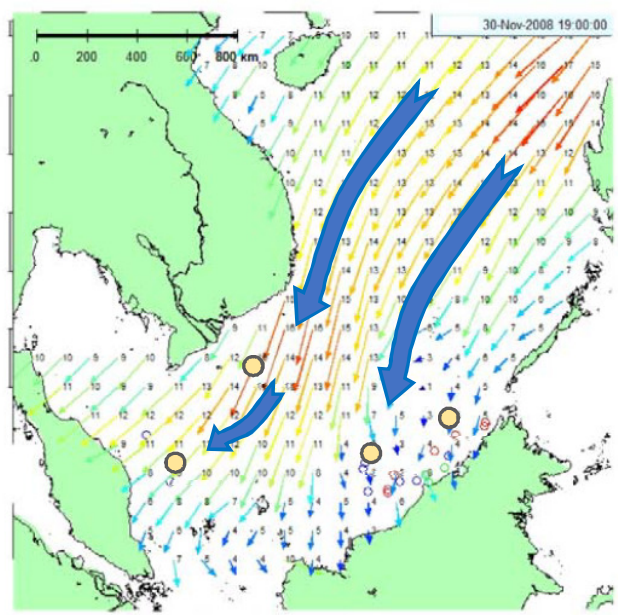

Figure 3: Wind patterns in South China Sea, South-Westerly Summer monsoon (left) and North-Easterly Winter monsoon (right) 
northern, eastern and southern boundaries. The input winds were derived from the National Centers for Environmental Prediction (NCEP) hindcast and adjusted based on available wind measurements and QUIKSCAT scatterometer satellite data. Tropical Cyclones winds were modelled separately and blended into the continuous wind hindcast. The hindcast winds and waves were validated using available measurements. While overall the validation showed the winds and waves were resolved accurately, the winds in the southern SCS region were found to be slightly overpredicted for extremes of the Northeasterly monsoons; the SEAFINE hindcast also appeared to be struggling to resolve periods of very low winds (below $5 \mathrm{~ms}^{-1}$ ). The small discrepancies in very low winds are not likely to have any material impact on the extremes.

Validation of wave data offshore Borneo and Peninsular Malaysia showed that the Hs was slightly overpredicted from the northeast, and underpredicted from the southwest and south; the peak spectral periods Tp were accurate for most directions.

For this study, the SEAFINE hindcast was sub-sampled over the southern SCS region (red box in Figure 1), with grid spacing of about $100 \mathrm{~km}$; this resulted in just under 1200 grid points over the study domain. Preference was given to grid points from the high-resolution grid, with an in-fill from coarser $28 \mathrm{~km}$ grid.

Cyclone tracks used in this study were extracted from the IBTrACS database for West Pacific region [23] and trimmed to match the duration of SEAFINE database (1956-2016, 59 years). The population was further reduced by including only tracks that passed through the study area (Figure 2). Note that IBTrACS database only includes storms that reached maximum sustained wind speed of 34 knots and above, compiled from the best-track data of the tropical warning centers in respective regions [23]; the track will typically include Tropical Depression phase of the storm.

\subsection{CEVA Methodology}

The CEVA method has been described in detail from a methodology perspective by [18], and from a user perspective by [1]. For this reason, we provide just an overview of the methodology in this section. For the current work, the objective of a CEVA analysis is estimation of the distribution of $\mathrm{N}$-year maxima for storm peak and sea state variables based on a sample of time-series for sea state variables. There are two key components of the modelling procedure: the first is estimation of a directional-seasonal extreme value model for storm peak variables (e.g. storm peak Hs), and isolation of so-called intrastorm trajectories describing the evolution of a storm relative to its peak; the second is simulation of storm peak events under the fitted model, and thereby simulation of sea state variables using the intra-storm trajectories. Careful quantification and propagation of uncertainties is performed throughout the analysis.

Periods corresponding to "statistical storms" are isolated as contiguous intervals of time between up- and down-crossings of a so-called "storm picking" threshold; when the time interval between adjacent storm periods is small, the storm periods are merged. Extreme value modelling for storm peaks proceeds using peaks-over threshold analysis. A directional-seasonal extreme value threshold is estimated using quantile regression. The rate of occurrence of threshold exceedances is characterised using a directional-seasonal Poisson distribution, and the size of threshold exceedances modelled using a non-stationary generalized Pareto distribution. Standardised intra-storm trajectories are isolated during the "storm picking" stage. Diagnostic plots for validation of the estimated model are presented in Section 3. These include seasonal and directional timeseries of winds and waves from SEAFINE hindcast, used as an input into CEVA model, as well as annual omni-directional return period values of winds and waves for a specific location, with the uncertainties included.

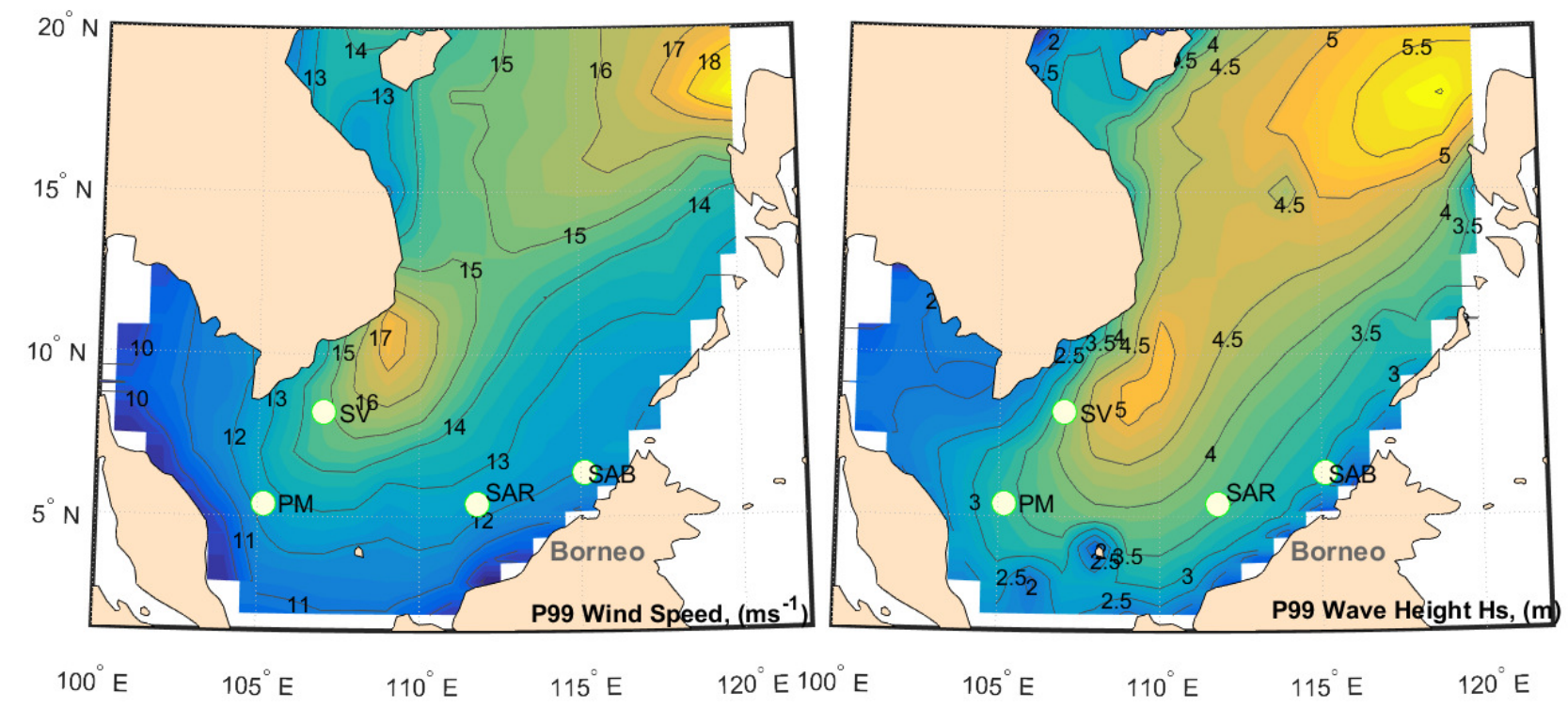

Figure 4: Spatial distribution of P99 exceedance of wind speed and Hs in South China Sea, from SEAFINE hindcast database 


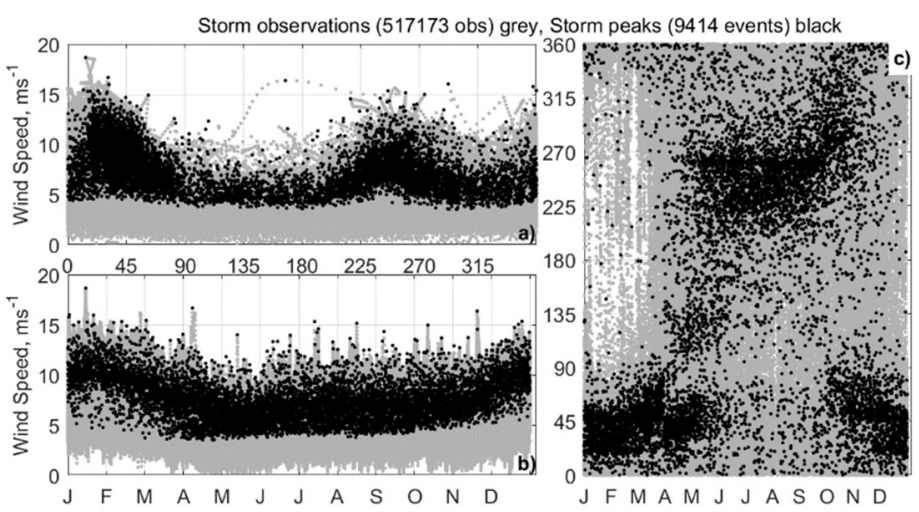

Figure 5: CEVA input winds, location offshore Sarawak (SAR)

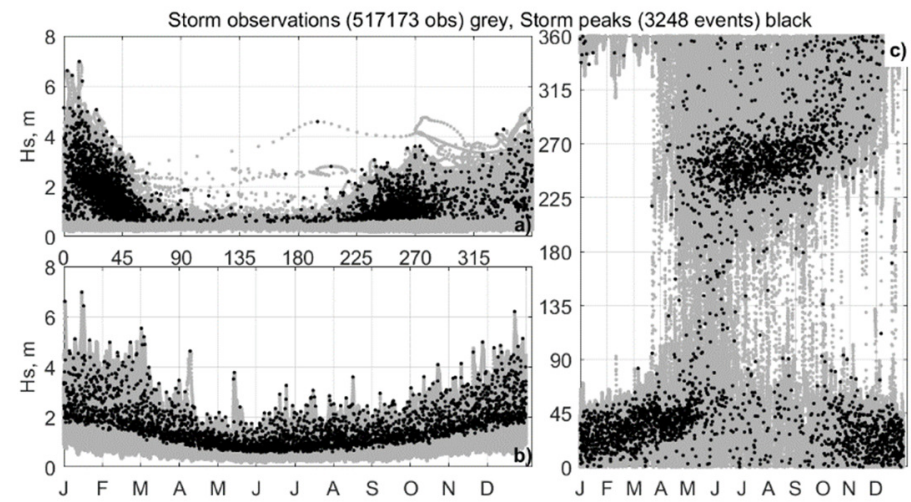

Figure 6: CEVA input waves, location offshore Sarawak (SAR)

Important user input for CEVA includes (a) specification of a time-interval for storm merging; (b) specification of a range of extreme value threshold non-exceedance probabilities to consider, and (c) specification of bounds for the upper and lower limits of generalised Pareto shape and scale parameters. The specification of the upper bound on generalised Pareto shape is particularly influential, since shape parameters exceeding zero imply that the extreme value distribution is unbounded to the right. Large numbers of diagnostic plots are generated at each stage of the analysis to guide the user through the methodology. Note that CEVA analysis is performed independently per location; specifically, no spatial smoothing is employed, and the extremal spatial dependence between variables at different spatial locations is not estimated, as the spatial CEVA code was not readily available at the time.

\section{RESULTS}

Figure 4 shows the spatial distribution of the $99^{\text {th }}$ percentile (P99) of 1-hour wind speed (left) and significant wave height Hs (right) across the SCS domain, derived from 59 years of continuous SEAFINE hindcast database. These values, sampled from the tail of the distribution, are indicative of the winds going into the CEVA analysis and in theory should show similar magnitudes and patterns as the lower RP extremal values.

The wind speed plot shows two district peaks of high winds, one offshore southern Vietnam, and one west of Luzon Island. The winds offshore southern Vietnam are amplified by the mountain range, which runs along the eastern edge of the
Indochina Peninsular ([24], [25]), both in summer and winter monsoons, and the $99^{\text {th }}$ percentile contour exceeds gale force winds $\left(17.5 \mathrm{~ms}^{-1}\right)$. Further south, along the Malaysian coastline, winds are weaker, which can be attributed to the proximity of the equator and the blocking effect of Peninsular Malaysia and Borneo Island landmasses on the monsoonal winds. The Gulf of Thailand is shielded from the seasonal monsoons by the Malaysian and Indochina Peninsulas, which is evident in the lower winds on the contours. Occasionally though, a tropical cyclone can pass through the area, with winds exceeding $40 \mathrm{~ms}^{-1}$ (Typhoon Sally 1972 or Typhoon Gay 1989, for example), Figure 2. While these events are so rare they don't even show in the $99^{\text {th }}$ wind percentiles, they still have a profound effect on extremes, as will be shown later in this study.

The $99^{\text {th }}$ percentile exceedances of wave heights are distributed in a similar manner to the winds, which is not surprising, as the wind speed, with fetch and duration are the key parameters affecting the wave heights and periods [11]. Highest waves are observed west of Luzon Island, where the Luzon Strait opening effectively creates an unlimited fetch into Pacific, and in the waters offshore southern Vietnam. The waves are also high in the central SCS, where high winds, long fetch (both in summer

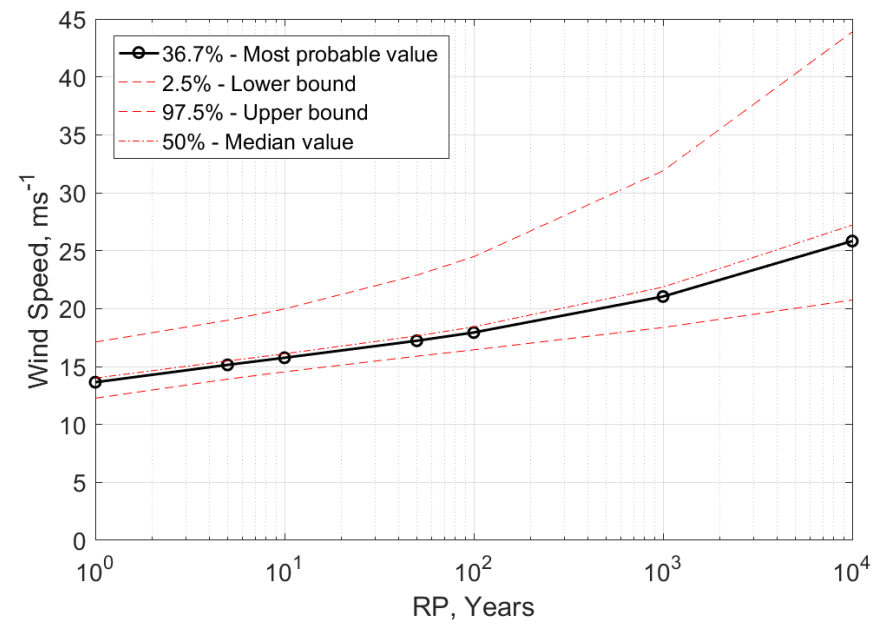

Figure 7: Wind Speed return period curve near SAR location

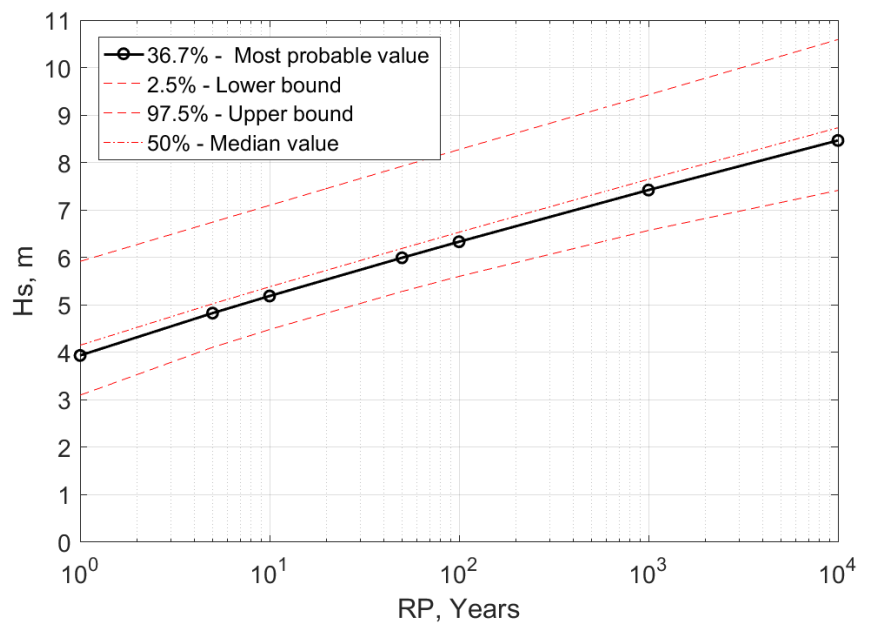

Figure 8: Hs return period curve near SAR location 

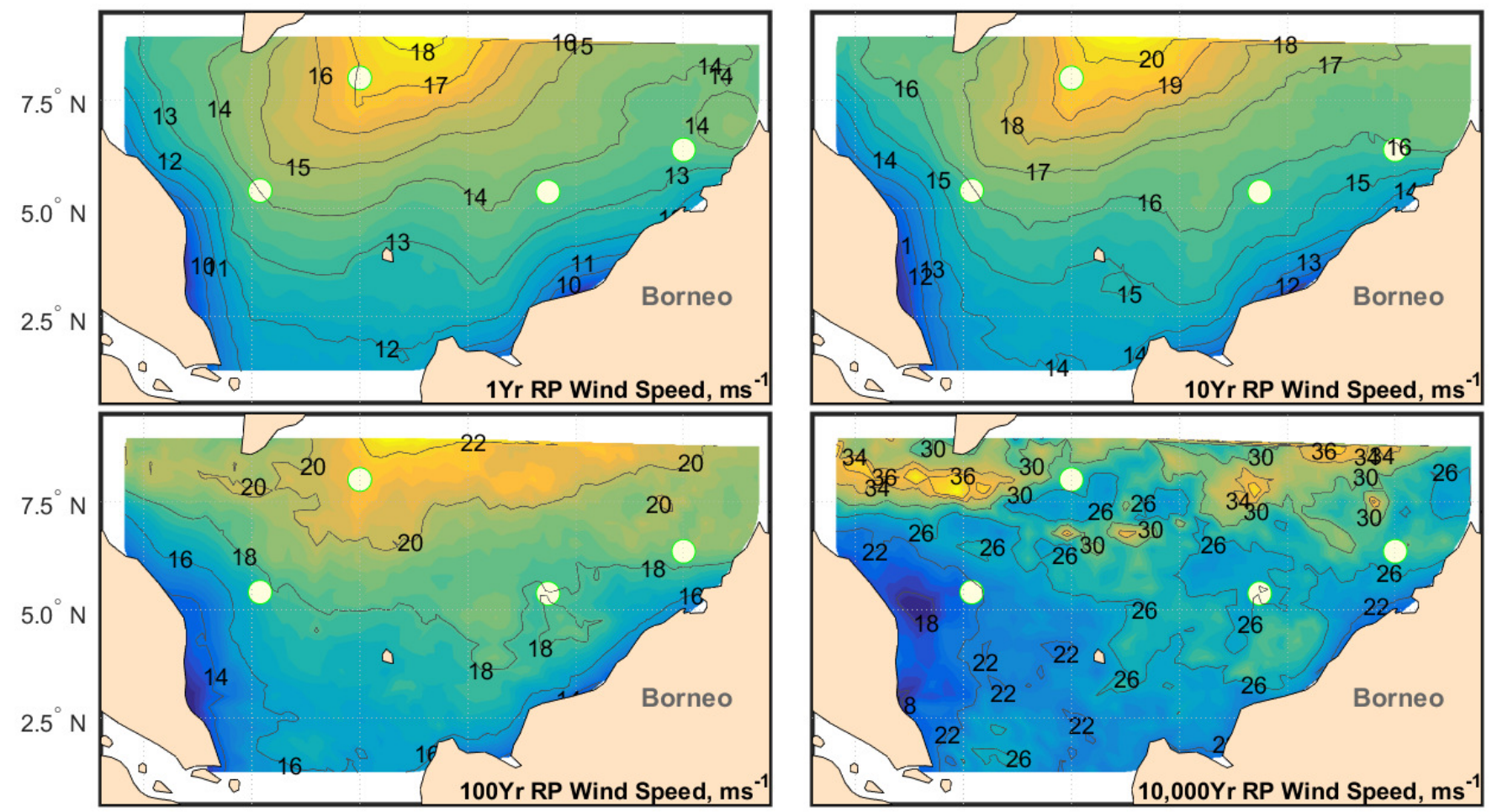

$102.5^{\circ}$ E $105.0^{\circ}$ E $107.5^{\circ}$ E $110.0^{\circ}$ E $112.5^{\circ}$ E $115.0^{\circ} \mathrm{E}$

$102.5^{\circ}$ E $105.0^{\circ}$ E $107.5^{\circ}$ E $110.0^{\circ}$ E $112.5^{\circ}$ E $115.0^{\circ} \mathrm{E}$

Figure 9: Contour plots of return period 1-hour Wind Speed in southern SCS
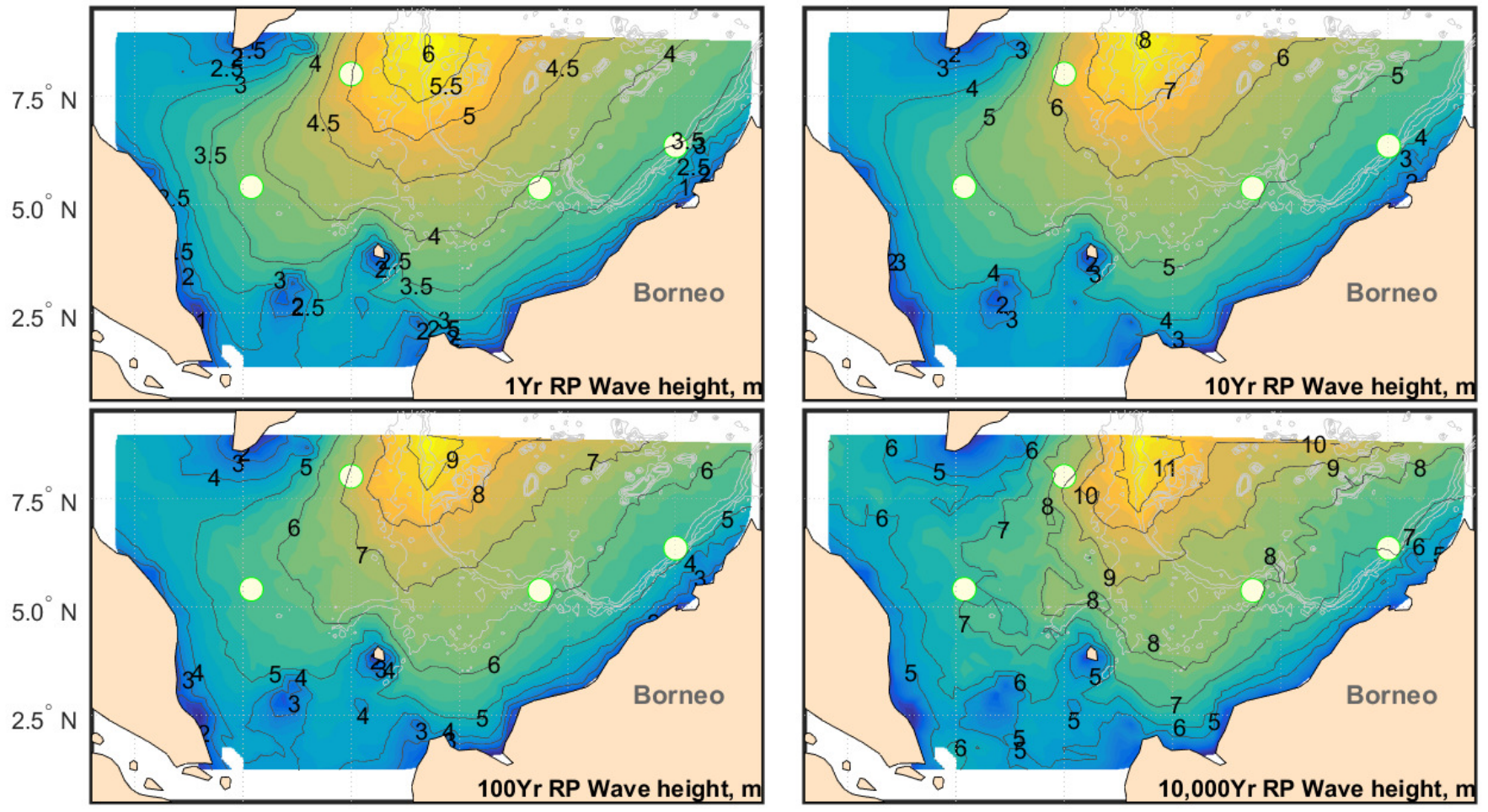

$102.5^{\circ} \mathrm{E} 105.0^{\circ} \mathrm{E} 107.5^{\circ} \mathrm{E} 110.0^{\circ} \mathrm{E} 112.5^{\circ} \mathrm{E} 115.0^{\circ} \mathrm{E}$

$102.5^{\circ}$ E $105.0^{\circ}$ E $107.5^{\circ}$ E $110.0^{\circ}$ E $112.5^{\circ}$ E $115.0^{\circ} \mathrm{E}$

Figure 10: Contour plots of return period Hs in southern SCS. Light grey lines are bathymetry contours. 
and winter) and deep water allow waves to grow. Over the continental shelf the waves are generally lower, due to combined effect of weaker winds, wave attenuation by the seabed friction, and sheltering effect of numerous atolls and coral reefs on the Sunda Shelf. The dearth of tropical cyclones in southern SCS also plays a role.

Seasonal and directional timeseries of winds (Figure 5) and waves (Figure 6) from SEAFINE hindcast, used as an input into CEVA model for a point offshore Sarawak, are shown as an example. Gray points are the timeseries, binned by months (a), directions (b) and months/directions (c); black dots show peaks of the storms selected for the extrapolation. Two distinct peaks are evident in wind directions: southwesterly to westerly (boreal summer monsoon) and north-northeasterly (boreal winter monsoon). The northeasterly winds are generally stronger.

Similar patterns can be observed from the monthly distributions (Figure 5b), with December, January and February experiencing the strongest winds, inter-monsoonal period of low winds in April and May, and characteristic southwesterly winds from June to September (summer monsoon), with occasional spikes associated with a passage of distant typhoons.

Waves offshore Sarawak show strong seasonal and directional variability (Figure 6). While in general they repeat wind patterns described above, northerly to northeasterly waves, associated with winter monsoon, are much higher compared to other directions, due to longer fetch and stronger winds from November to early March. The waves are very low in April and May (inter-monsoonal period), then increase from June to September, as southwesterly winds pick up. In boreal summer the wave directions are predominantly westerly to southwesterly; wave heights are smaller due to shorter fetch and weaker winds.

Figure 7 and Figure 8 show estimated annual omnidirectional return period values at a SAR location for wind speed and Hs, respectively. For wind speed, uncertainties increase at the higher return values, while for the waves the spread of the uncertainties is relatively constant. This is not surprising, since the estimated distribution of shape parameter for wind speed includes positive values (and hence a long tail for wind speed). In contrast, estimated shape parameters for Hs are predominantly negative (corresponding to a shorter tail).

Figure 9 shows contour plots of return period annual omnidirectional wind speed for 1, 10, 100 and 10,000-year return periods. These have been derived from independent location-bylocation CEVA analysis for nearly 1200 locations in the study area. Lower return values $(1,10,100$ years) are dominated by monsoonal winds, generally repeating the spatial distribution of $99^{\text {th }}$ percentile winds, Figure 4). The 10,000-year wind return value estimates show much noisier patterns, with regions of stronger winds coinciding with the passage of rare tropical cyclones. This is particularly evident in the Gulf of Thailand (Typhoon Sally 1972, Gay 1989), offshore Singapore (Vamei 2001), north of Sarawak (Typhoon Percy 1983) and offshore Sabah (TS Greg 1996), Figure 2.

Figure 10 shows contour plots of return values for Hs. Bathymetry contours for 100, 250, 500 and $1000 \mathrm{~m}$ are shown as gray lines in the background. The spatial variation of return value is smoother than for wind, with obvious coastal effects. Likewise, the spatial pattern of return values appears similar for all return periods considered.

The monthly 1- and 100-year return period values for four selected locations are presented in Figure 11: top panels are the winds speed at 1 and 100-year return period, bottom panels are Hs. The winds show strong seasonal and spatial variability. Not surprisingly, the strongest winds are predicted for a Southern Vietnam location, peaking in boreal winter months during Northeasterly monsoon. Other locations show similar patterns,

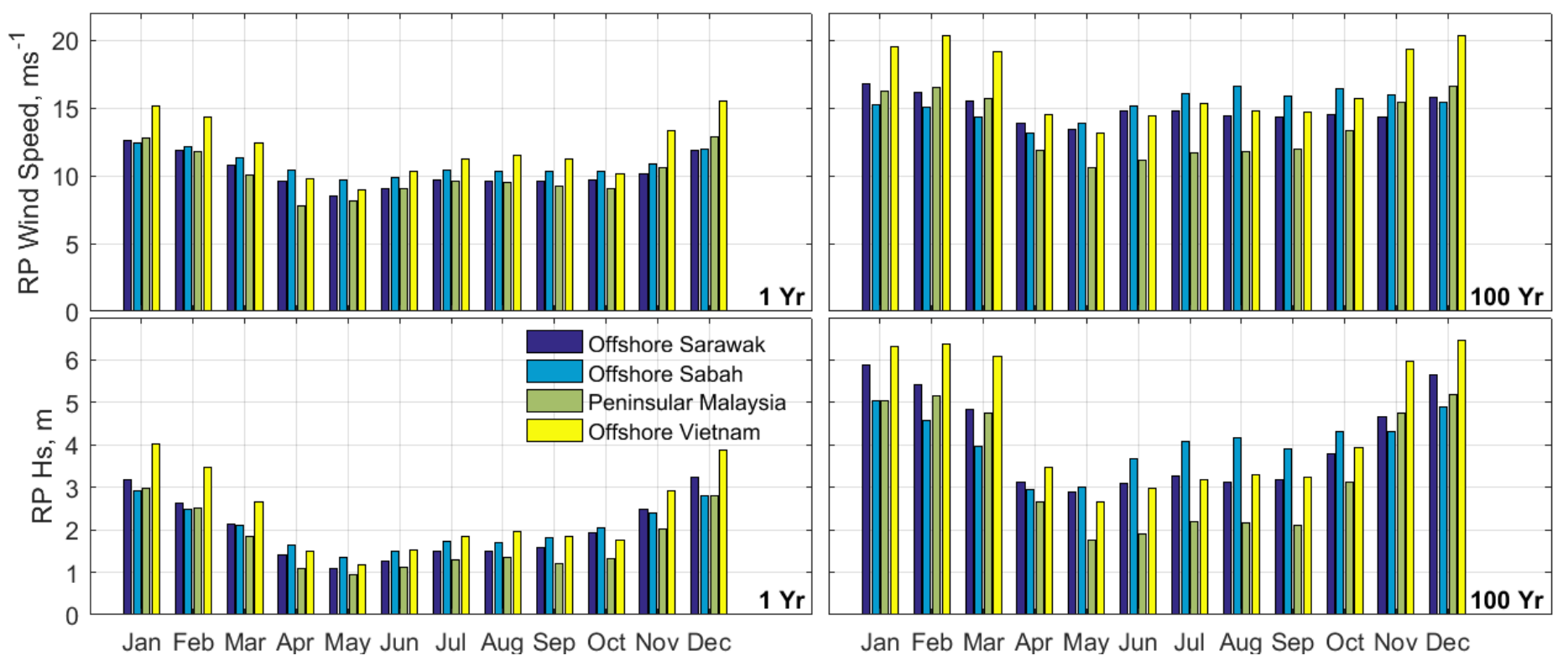

Figure 11: Monthly 1- and 100- year return period wind speed (top) and Hs (bottom) 


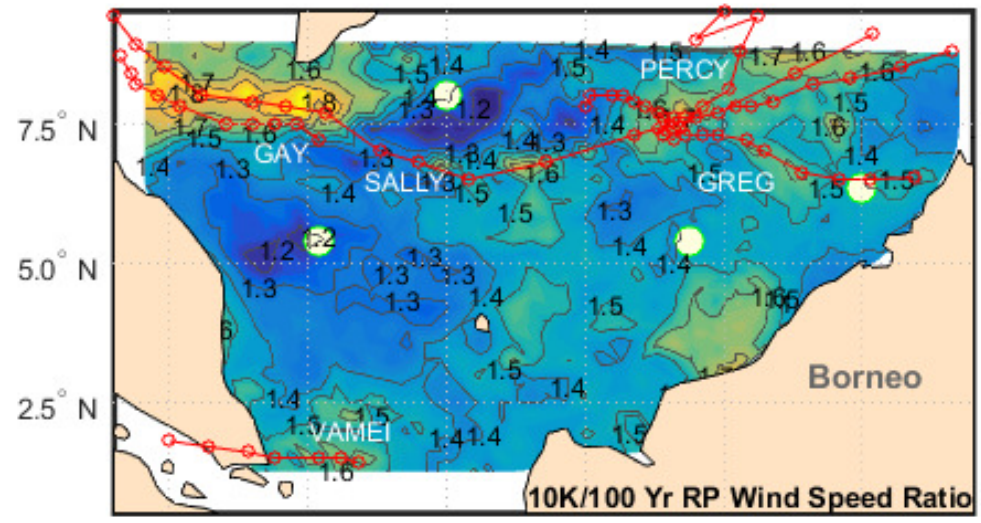

$102.5^{\circ}$ E $105.0^{\circ}$ E $107.5^{\circ}$ E $110.0^{\circ}$ E $112.5^{\circ}$ E $115.0^{\circ} \mathrm{E}$

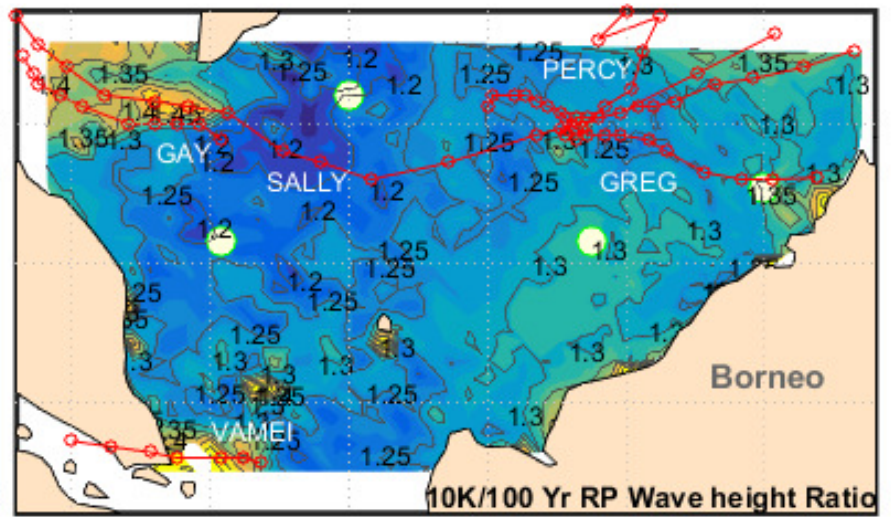

$102.5^{\circ}$ E $105.0^{\circ}$ E $107.5^{\circ}$ E $110.0^{\circ}$ E $112.5^{\circ}$ E $115.0^{\circ} \mathrm{E}$

Figure 12: Ratios of 10,000/100-year return period for wind speed and $\mathrm{Hs}$

but the estimated winds speeds are weaker. The exception is Sabah offshore location (SAB), where the highest return period values are predicted for summer months. This might be due to enhancement of the southwesterly winds by the Borneo landmass. In contrast, return values for wind in summer months offshore Peninsular Malaysia (PM) are significantly lower, attributable to the sheltering effect of the PM.

In addition to wind strength, monthly return values for waves are impacted by fetch length, storm durations and bathymetric effects. Across the region, waves are highest from December to February, throughout the Northeasterly monsoon. In these months, highest waves are observed offshore Vietnam, followed by Sarawak and off Peninsular Malaysia. In boreal summer, waves offshore PM are smallest, due to weaker winds and shorter fetch lengths. Highest waves are expected offshore Sabah, where stronger southwesterly winds and longer fetch enhance extreme values for the waves.

Figure 12 shows contours of 10,000-year to 100-year values for winds (left) and waves (right). Five selected cyclone tracks (Sally 1972, Percy 1983, Gay 1989, Greg 1996 and Vamei 2001) are overlaid in red. The spatial map of ratios for wind speed shows what appears to be correlation the position of tropical cyclone tracks. Locations with weak cyclonic activity (offshore Peninsular Malaysia, for example) suggest an average 10,000year to 100-year ratio of 1.2-1.3. North of Borneo Island and offshore Sabah the values increase to 1.5-1.6, corresponding to the tracks of tropical storm Greg 1996, typhoon Percy 1983, and the weak tropical depression which passed over Sarawak shelf in 1961. In the Gulf of Thailand, the ratio increases to 1.7-1.8, following tracks of typhoons Sally 1972 and Gay 1989. Similar observation can be made for offshore Singapore, where elevated ratios of approximately 1.6 correspond to the track of Typhoon Vamei 2001. Ratios of 10,000-year to 100-year Hs are shown on the right panel in Figure 12. Wave ratios show less spatial variability compared to winds, but trends are still present. Offshore Peninsular Malaysia, ratios for $\mathrm{Hs}$ are around 1.2, increasing to around 1.3 offshore Borneo. In the Gulf of Thailand, ratios increase to 1.4, with a maximum centered along the tracks of typhoons Sally 1972 and Gay 1989.

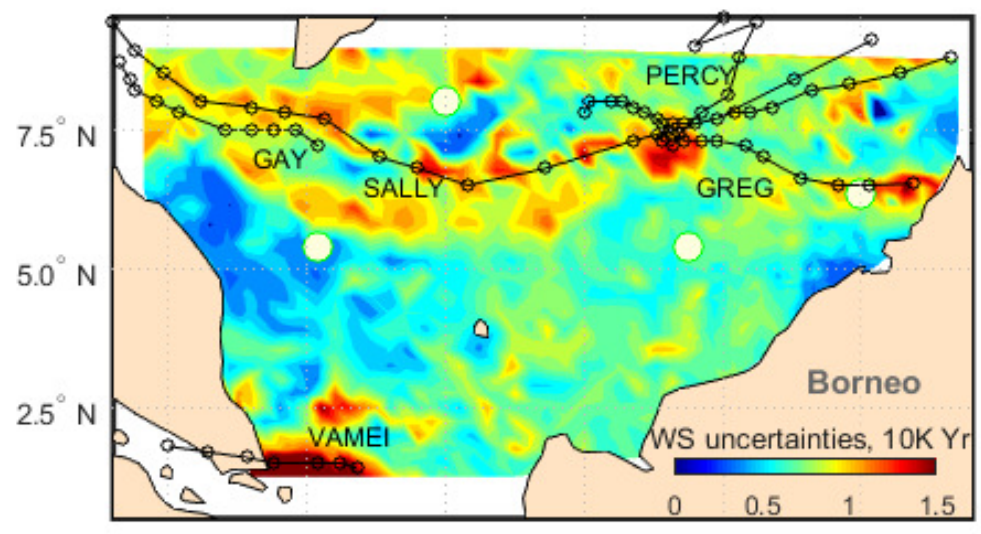

$102.5^{\circ}$ E $105.0^{\circ}$ E $107.5^{\circ}$ E $110.0^{\circ}$ E $112.5^{\circ}$ E $115.0^{\circ} \mathrm{E}$

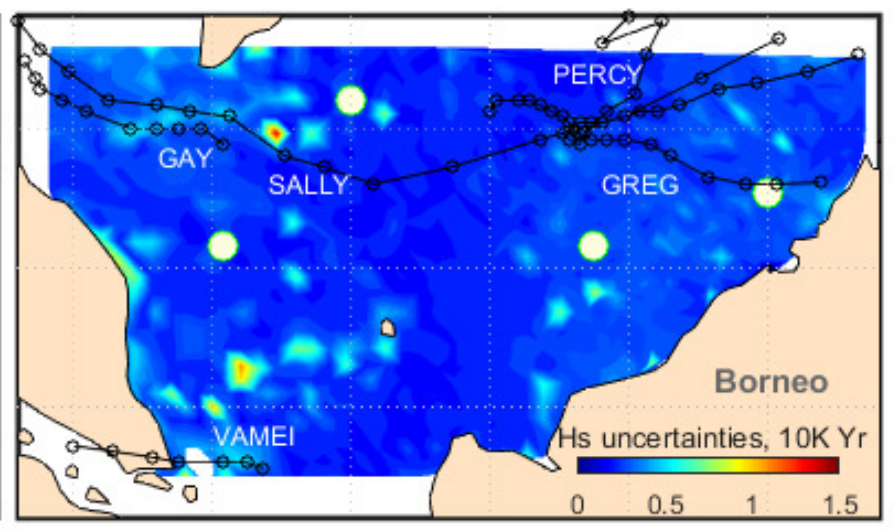

$102.5^{\circ} \mathrm{E} 105.0^{\circ} \mathrm{E} 107.5^{\circ} \mathrm{E} 110.0^{\circ} \mathrm{E} 112.5^{\circ} \mathrm{E} 115.0^{\circ} \mathrm{E}$

Figure 13: Uncertainties at 10,000-year return period values for wind speed and $\mathrm{Hs}$ 


\section{DISCUSSION}

To demonstrate the uncertainties associated with return values (for Hs and wind speed, independently per grid location) at the 10,000-year return period, the most probable value (P36.7) of the return value was subtracted from the upper P97.5 quantile, and the difference divided by the most probable value to normalise it, so that: $\alpha=\left(\mathrm{P}_{\text {upper }}-\mathrm{P}_{\mathrm{mp}}\right) / \mathrm{P}_{\mathrm{mp}}$. Figure 13 shows normalised uncertainties of 10,000-year values of wind speed (left) and $\mathrm{Hs}$ (right). Zero values of $\alpha$ would indicate no uncertainty at all, values exceeding 1 would point to large uncertainties. For wind speed, the highest uncertainties are observed along the tracks of individual cyclonic events, where $\alpha$ often exceed 1. The uncertainties for waves are much smaller, with $\alpha$ around $0.1-0.2$.

When estimating extreme values, it is important to understand the phenomena which control the shape of the extreme value tail and the growth of uncertainties. Tail shape could be driven by epistemic uncertainty, including sample size, model choice, parameter estimation and specification of bounds for generalised Pareto parameters. Extreme value analysis requires that we fit statistically independent identically distributed extreme events, which share similar physical properties and have comparable occurrence rates. What happens if we mix two distinct storm populations in the dataset (monsoons and typhoons, for example), as these have different occurrence rates and statistical behavior?

If we do not represent the actual characteristics of the environment adequately in a statistical model, we introduce epistemic uncertainty. However, tail shape differences could be aleatory; that is, there could be real physical differences in the characteristics of environmental extremes at those locations. Monsoons are the main process driving the extremes of winds and waves in the southern SCS. During boreal winter, northeasterly monsoonal events occur roughly once every 7-10 days, driven by the formation and movement of high-pressure systems over China and eastern Russia. In boreal summer monsoonal events are weaker and are associated with the strengthening of the seasonal southwesterly winds. Locations with the predominantly monsoonal populations tend to have a 'flatter' return period curve, for example region offshore Peninsular Malaysia, with 10,000 to 100 -year ratio averaging 1.3 for the winds and 1.2-1.25 for waves (Figure 12).

Tropical cyclones in the southern SCS, on the other hand, are much rarer. For example, there were only 111 storm events identified in the southern SCS study domain (Figure 2) from the 60-year long IBTrACS database for the West Pacific region [23]; this is roughly 1.85 events per year. Most of these events were just Tropical Depressions, with only few systems reaching tropical storm and typhoon strength. For the winds, it appears that if marginal extremes are calculated from the mixed population, with most of extremes from monsoonal events and only a few contributions from tropical cyclones, the ratio of 10.000 to 100 -year value increases significantly (1.5-1.7), along with the associated uncertainty. For the waves, the ratio also increases to 1.3-1.4 in regions where tropical cyclones are active, although the associated uncertainty remains low. This can be attributed to smaller differences between large monsoonal events (with long fetch) and relatively weak tropical cyclones, thus more homogenous population.

The challenge of fitting marginal extremes in regions with mixed storm populations remains. Ideally, we should isolate the populations and fit them separately, recombining the results later, but this is often impractical for locations with small rate of occurrence of tropical cyclones (southern SCS, northern Australia, eastern Gulf of Mexico, etc.). The limiting case is the impact of a single extreme storm ("black swan event") on the extrapolation. As we can see from the example of typhoon Vamei, even equatorial regions can experience tropical cyclones. As a result, the return period curve steepened significantly, along with the underlying uncertainty.

There is a large body of empirical evidence (personal experience of authors, and published work such as [26] for the extreme winds and [27] for the extreme waves) suggesting that the range of "typical" values of generalised Pareto shape parameter observed for $\mathrm{Hs}$ is different to that observed for wind speed. For this reason, in the current work, an upper bound of +0.2 for generalised Pareto shape was specified for wind speed analysis, compared to 0.0 for Hs. In some cases, increase of upper bound for waves to 0.1 is justified, leading to slightly more conservative Hs values. During model testing, we confirmed that the upper end point constraint was not too influential on the distributions of generalised Pareto shape parameter estimated. Nevertheless, it is apparent that specification of bounds for generalised Pareto shape (or specification of a prior distribution in Bayesian analysis) is a critical but problematic choice in metocean applications. As much physical evidence as possible (e.g. relating to water depth and wave steepness limitations for waves) should be incorporated as possible.

\section{ACKNOWLEDGMENTS}

This work was supported by Petroliam Nasional Berhad (PETRONAS) and Sarawak Shell Bhd under ASC research funding. We thank M Nasir B Abdullah for the ongoing support of this project. We would also like to thank Kevin Ewans, Jason McConochie and Matthew Jones for valuable discussions during the preparation of the manuscript.

\section{REFERENCES}

[1] Feld, G, Randell, D, Ross, E, Jonathan, P. 2018. "Design conditions for waves and water levels using extreme value analysis with covariates". Ocean Engineering, in press

[2] Chang CP, Krishnamurti TN. 1987. "Monsoon Meteorology". Oxford University Press.

[3] Wang P, Clemens S, Beaufort L, Braconnot P, Ganssen G, Jian Z, et al. 2005. "Evolution and variability of the Asian monsoon system: state of the art and outstanding issues". Quat Sci Rev.24: 595-629.

[4] Wang B, Huang F, Wu Z, Yang J, Fu X, Kikuchi K. 2009. "Multi-scale climate variability of the South China Sea monsoon: A review". Dyn Atmos Oceans.47: 15-37. 
[5] Anokhin V, Ewans K. 2018. "Estimating storm surge and reservoir subsidence of offshore platforms using WaveRadar REX SAAB sensors". Offshore Technology Conference OTC-Asia. doi:10.4043/28400-ms

[6] Lin Y-L, Lee C-S. 2011. "An analysis of tropical cyclone formations in the South China Sea during the late season". Mon Weather Rev.139: 2748-2760.

[7] Chia HH, Ropelewski CF. 2002. "The interannual variability in the genesis location of tropical cyclones in the Northwest Pacific". J Clim.15: 2934-2944.

[8] Zuki ZM, Lupo AR. 2008. "Interannual variability of tropical cyclone activity in the southern South China Sea". J Geophys Res.113. doi:10.1029/2007jd009218

[9] Zehr RM. 1992. "Tropical cyclogenesis in the Western North Pacific". NOAA report.

[10] Chang C-P. 2003. "Typhoon Vamei: An equatorial tropical cyclone formation". Geophys Res Lett. 30 doi:10.1029/2002g1016365

[11] Hasselmann, K., Barnett, T.P., Bouws, E., Carlson, H., Cartwright, D.E., Enke, K., Ewing, J.A., Gienapp, H., Hasselmann, D.E., Kruseman, P., Meerburg, A., Müller, P., Olbers, D.J., Richter, K., Sell, W., Walden, H. 1973. "Measurements of wind-wave growth and swell decay during the Joint North Sea Wave Project (JONSWAP)". Hydr. Eng. Reports, Deutsches Hydrographisches Institut

[12] Amurol, S., Ewans, K.C. 2019. "The effect of swell on wave spectra of extreme sea states offshore Sarawak, Malaysia". Ocean Eng., in prep.

[13] Koseki S, Koh T-Y, Teo C-K. 2014. "Borneo vortex and mesoscale convective rainfall". Atmos Chem Phys.14: 4539_ 4562.

[14] ISO 19902:2007 "Petroleum and natural gas industries Fixed steel offshore structures", Dec 2007, Ed. 1, pp 622

[15] Efthymiou M, van de Graaf JW. 2011. "Reliability and (Re)Assessment of Fixed Steel Structures". In Proceedings of the ASME 2011 30th International Conference on Ocean, Offshore and Arctic Engineering (Vol. 1, pp. 10

[16] Tucker, M. J. and Pitt, E. G. 2001. "Waves in ocean engineering (1st ed)". Elsevier, Amsterdam; New York

[17] ISO 19901-1:2015 "Petroleum and natural gas industries - Specific requirements for offshore structures -- Part 1: Metocean design and operating considerations", Oct 2015, Ed. 2, pp206

[18] Feld G, Randell D, Wu Y, Ewans K, Jonathan P. 2015. "Estimation of storm peak and intrastorm directionalseasonal design conditions in the North Sea". J Offshore Mech Arct Eng.137: 021102.

[19] Randell D, Feld G, Ewans K, Jonathan P. 2015. "Distributions of return values for ocean wave characteristics in the South China Sea using directional-seasonal extreme value analysis". Environmetrics. 26: 442-450.

[20] Raghupathi L, Randell D, Jonathan P, Ewans KC. 2016. "Consistent design criteria for South China Sea with a largescale extreme value model". Offshore Technology Conference OTC - Asia. doi:10.4043/26668-ms
[21] Li P, Zhu Q, Zhou C, Li L, Li H. 2017. "Metocean design criteria considerations in South China sea by adopting multivariate extreme value theory. Volume 1: Offshore technology". doi:10.1115/omae2017-62541

[22] Oceanweather Inc., Metocean Study: SEAFINE Retrieved from Oceanweather: http://www.oceanweather.com

[23] Knapp KR, Kruk MC, Levinson DH, Diamond HJ, Neumann CJ. 2010. “The International Best Track Archive for Climate Stewardship (IBTrACS)". Bull Am Meteorol Soc.91: 363-376.

[24] Xie S-P. 2003 "Summer upwelling in the South China Sea and its role in regional climate variations". J Geophys Res.108. doi:10.1029/2003jc001867

[25] Liu Q, Kaneko A, Jilan S. 2008. "Recent progress in studies of the South China Sea circulation". J Oceanogr. 64:753-762.

[26] Simiu, E. and Heckert, A. 1996. "Extreme Wind Distribution Tails: A Peak Over Threshold Approach". J. Structural Engineering, ASCE, 122(5), 539-547.

[27] Méndez, F.J., Menéndez, M., Luceño, A., \& Losada, I.J. 2006. "Estimation of the long-term variability of extreme significant wave height using a time-dependent Peak Over Threshold (POT) model". J Geophys Res., VOL. 111, C07024, doi:10.1029/2005JC003344 